\title{
Microsurgery for cerebral arteriovenous malformations: subgroup outcomes in a consecutive series of 288 cases
}

\author{
*Johannes Schramm, MD, ${ }^{1}$ Karl Schaller, MD, ${ }^{2}$ Jonas Esche, MSc, ${ }^{3}$ and Azize Boström, MD \\ ${ }^{1}$ Medical Faculty and ${ }^{3}$ Department of Neurosurgery, Medical School, University of Bonn, Bonn, Germany; and ${ }^{2}$ Department of \\ Neurosurgery, University of Geneva, Medical Center, Geneva, Switzerland
}

\begin{abstract}
OBJECTIVE The objective of this study was to review the outcomes after microsurgical resection of cerebral arteriovenous malformations (AVMs) from a consecutive single-surgeon series. Clinical and imaging data were analyzed to address the following questions concerning AVM treatment in the post-ARUBA (A Randomized Trial of Unruptured Brain Arteriovenous Malformations) era. 1) Are the patients who present with unruptured or ruptured AVMs doing better at long-term follow-up? 2) Is the differentiation between Ponce Class A (Spetzler-Martin Grade I and II) patients versus Ponce Class B and C patients (Spetzler-Martin Grade III and IV) meaningful and applicable to surgical practice? 3) How did the ARUBA-eligible patients of this surgical series compare with the results reported in ARUBA?
\end{abstract}

METHODS Two hundred eighty-eight patients with cerebral AVMs underwent microsurgical resection between 1983 and 2012 performed by the same surgeon (J.S.). This is a prospective case collection study that represents a consecutive series. The results are based on prospectively collected, early-outcome data that were supplemented by retrospectively collected, follow-up data for $94 \%$ of those cases. The analyzed data included the initial presentation, Spetzler-Martin grade, obliteration rates, surgical and neurological complications, and frequency of pretreatment with embolization or radiosurgery. The total cohort was compared using "small-AVM," Spetzler-Martin Grade I and II, and ARUBA-eligible AVM subgroups.

RESULTS The initial presentation was hemorrhage in $50.0 \%$ and seizures in $43.1 \%$ of patients. The series included 53 Spetzler-Martin Grade I (18.4\%), 114 Spetzler-Martin Grade II (39.6\%), 90 Spetzler-Martin Grade III (31.3\%), 28 SpetzlerMartin Grade IV (9.7\%), and 3 Spetzler-Martin Grade V (1.0\%) AVMs. There were 144 unruptured and 104 ARUBAeligible cases. Preembolization was used in 39 cases (13.5\%). The occlusion rates for the total series and small AVM subgroup were $99 \%$ and $98.7 \%$, respectively. The mean follow-up duration was 64 months. Early neurological deterioration was seen in $39.2 \%$ of patients, of which $12.2 \%$ had permanent and $5.6 \%$ had permanent significant deficits, and the mortality rate was $1.7 \%(n=5)$. Outcome was better for patients with AVMs smaller than $3 \mathrm{~cm}$ (permanent deficit in $7.8 \%$ and permanent significant deficit in $3.2 \%$ of patients) and Ponce Class A status (permanent deficit in $7.8 \%$ and significant deficit in 3.2\% of patients). Unruptured AVMs showed slightly higher new deficit rates (but 0 instances of mortality) among all cases, and in the small AVM and Ponce Class A subgroups. Unruptured Spetzler-Martin Grade I and II lesions had the best outcome (1.8\% permanent significant deficit), and ARUBA-eligible Spetzler-Martin Grade I and II lesions had a slightly higher rate of permanent significant deficits (3.2\%).

CONCLUSIONS Microsurgery has a very high cure rate. Focusing microsurgical AVM resection on unruptured lesions smaller than $3 \mathrm{~cm}$ or on Spetzler-Martin Grade I and II lesions is a good strategy for minimizing long-term morbidity. Well-selected microsurgical cases lead to better outcomes than with multimodal interventions, as in the ARUBA treatment arm, or conservative treatment alone. Long-term prospective data collection is valuable.

https://thejns.org/doi/abs/10.3171/2016.4.JNS153017

KEY WORDS brain arteriovenous malformation; AVM; microsurgery; ARUBA eligible; unruptured AVM; vascular disorders

ABBREVIATIONS ARUBA = A Randomized Trial of Unruptured Brain Arteriovenous Malformations; AVM = arteriovenous malformation; mRS = modified Rankin Scale. SUBMITTED December 25, 2015. ACCEPTED April 6, 2016.

INCLUDE WHEN CITING Published online June 10, 2016; DOI: 10.3171/2016.4.JNS153017.

* Drs. Schramm and Boström contributed equally to this work. 
$\mathrm{T}$ HE treatment of cerebral arteriovenous malformations (AVMs) continues to be a matter of debate despite major advances in the last 3 decades with the advent of radiosurgery and microsurgery. Although AVMs are rare, they carry a certain life-long risk for stroke due to rupture, which has been reported to occur at a frequency of about $2 \%$ to $4 \%$ per year. ${ }^{5,6}$

While there is general agreement that ruptured AVMs need to be completely obliterated or excised, the treatment of unruptured AVMs has been reviewed and discussed intensively following the recent trial on medical management versus interventional therapy for unruptured AVMs, the so-called ARUBA (A Randomized Trial of Unruptured Brain Arteriovenous Malformations) study. ${ }^{12}$ This randomized trial of medical management versus interventional management allowed any intervention to be used (or any combination thereof), and concluded that noninterventional management was superior to intervention. Only 5 of 322 patients underwent microsurgical treatment alone; however, another 13 of 322 patients underwent microsurgery as part of multimodal therapy. Although, in general, prospective randomized clinical trials are considered to be superior to single-center series, several authors criticized the low number of patients who underwent microsurgical resection alone and concluded that 2 treatment modalities known for a high rate of incomplete AVM occlusion (embolization and radiosurgery) led to the result that interventional treatment might be easily misunderstood as rendering microsurgery ineffective., $, 7,11,16,20,23,26$ Later attention was focused on lower Spetzler-Martin grades, where outcome was found to be better, and also on subgroups who would have fulfilled the eligibility criteria for the ARUBA study. A few series on ARUBA-eligible cases are available, which show that microsurgery is still a viable tool for certain subgroups. ${ }^{2,12,16,21,25}$

This patient series was treated surgically by a single surgeon at 2 institutions between 1983 and 2012 and includes every AVM removed by that surgeon. This study aims to contribute data on outcomes after microsurgery, including subgroup analyses for small, unruptured, ARUBA-eligible and Spetzler-Martin Grade I and II AVMs.

\section{Methods \\ Patient Collection}

All patients who ever harbored an AVM that was removed by the senior surgeon (J.S.) between 1983 and 2012 (between 1983 and 1989 in Erlangen and between 1990 and 2012 in Bonn) were included $(\mathrm{n}=288)$. Since 1985, all data have been collected in a database, which was maintained and supervised by 4 different staff neurosurgeons over 27 years. Thus, since 1985, immediate, postoperative, and 3-month outcome data, and also partial 6-month outcomes, have been collected prospectively. Between 2012 and 2015, all charts were reexamined and follow-up notes were reviewed, which included reviewing charts at the former institution. In this way, the patient database was updated by 2 of the authors from charts and telephone interviews for 270 cases (94\%). The stored data included patient demographics, lesion size, Spetzler-Martin grade and location of the AVM, presence of deep venous drainage, clinical presentation, use of preoperative embolization, the occlusion rate on early postoperative angiography, early postoperative deficits, 3- and partial 6-month outcome data, and general surgical complications.

Additional data on the AVM outpatient caseload were available for the period from 1990 to 2009. Here, AVM patients $(n=281)$ were seen and advised on treatment, but they did not undergo surgery. In the same period, AVMs (n = 339) were surgically treated in Bonn, of which 226 were treated by the senior author and are part of this series. A subset of 150 cases until 1995 were included from this patient group, but only short-term outcomes were previously analyzed. ${ }^{23}$

\section{Outcome Assessment}

Neurological assessment was performed in the immediate postoperative period until discharge and then at 3 and 6 months. Long-term follow-up was available for $94 \%$ of patients, with a median of 64 months (range $0-326$ months). Each patient underwent early control angiography, usually after about 1 week, but in the last 11 years this usually occurred immediately after surgery. Data from the cases in the first 2 years were retrospectively obtained from the patient charts, and since 1985 data were prospectively collected. Complications were classified as surgical, i.e., problems resulting from surgery without impacting the neurological findings, such as pneumonia, urinary tract infection, wound infection, and pulmonary embolus. Neurological deterioration was classified as early, permanent, permanent significant, or nonsignificant. The modified Rankin Scale (mRS) score was assessed retrospectively, as at the very beginning of data collection this scoring system was not established for use in routine clinical diagnostics. Whenever we felt uncertain about the correct scoring, we preferred to use the higher score in order to not overestimate good outcomes. Hence, the clinical condition at the last available follow-up was classified into 2 groups according to $\mathrm{mRS}$ score: $\mathrm{mRS}$ score $<2(70.7 \%)$ and $\mathrm{mRS}$ score $\geq 2(29.3 \%)$. This includes poorer preoperative $\mathrm{mRS}$ score $\geq 2$ due to hemorrhage.

\section{Treatment Modalities}

Since the case collection covers a period of 27 years, cases are included from a time period when embolization was not so common and radiosurgery had not yet become widely established. After 1989, in the early period in Bonn, we employed embolization more frequently. Overall, microsurgery alone was used in 244 cases $(84.7 \%)$ and presurgical embolization in 39 cases (13.5\%). The series included 11 cases that had undergone prior radiosurgery $(3.8 \%)$.

\section{Presurgical Workup, Resection Technique, and Postoperative Management}

Standard workup included MRI and digital 4-vessel angiography. Whenever possible, cases were treated after recovery from the acute effects, thereby allowing for careful planning and elective timing. Microsurgical resection of an AVM consisted of circumferential dissection of the nidus with early identification and occlusion 
TABLE 1. Data of the study cohort, small AVM subgroup, and unruptured subgroups*

\begin{tabular}{|c|c|c|c|c|}
\hline Variable & $\begin{array}{c}\text { All } \\
\text { AVMs }\end{array}$ & $\begin{array}{l}\text { Unruptured } \\
\text { AVMs }\end{array}$ & $\begin{array}{l}\text { Small } \\
\text { AVMs } \\
(<3 \mathrm{~cm})\end{array}$ & $\begin{array}{l}\text { Unruptured } \\
\text { Small AVMs }\end{array}$ \\
\hline Total & 288 & 144 & 154 & 62 \\
\hline \multicolumn{5}{|l|}{ Sex } \\
\hline Male & $154(53.5)$ & $76(52.8)$ & $80(52.3)$ & $27(43.5)$ \\
\hline Female & $134(46.6)$ & $68(47.2)$ & $74(47.7)$ & $35(56.5)$ \\
\hline Mean age, yrs & 35.3 & 35.3 & 35.8 & 35.5 \\
\hline \multicolumn{5}{|l|}{$\begin{array}{l}\text { Spetzler-Martin } \\
\text { grade }\end{array}$} \\
\hline I & $53(18.4)$ & $26(18.1)$ & 51 (32.9) & $25(40.3)$ \\
\hline II & $114(39.6)$ & $52(36.1)$ & $75(48.4)$ & $29(46.8)$ \\
\hline III & $90(31.3)$ & $46(31.9)$ & $28(18.7)$ & $8(12.9)$ \\
\hline IV & $28(9.7)$ & $18(12.5)$ & $0(0)$ & $0(0)$ \\
\hline V & $3(1.0)$ & $2(1.4)$ & $0(0)$ & $0(0)$ \\
\hline \multicolumn{5}{|l|}{ Size } \\
\hline$<3 \mathrm{~cm}$ & $154(53.5)$ & $62(43.1)$ & $154(100)$ & $62(100)$ \\
\hline $3-6 \mathrm{~cm}$ & $129(44.8)$ & $79(54.9)$ & $0(0)$ & $0(0)$ \\
\hline$>6 \mathrm{~cm}$ & $5(1.7)$ & $3(2.1)$ & $0(0)$ & $0(0)$ \\
\hline \multicolumn{5}{|l|}{ Venous drainage } \\
\hline $\begin{array}{c}\text { Deep (w/ or w/o } \\
\text { superficial } \\
\text { drainage) }\end{array}$ & $101(34.7)$ & $50(34.7)$ & $44(28.4)$ & $15(24.2)$ \\
\hline \multicolumn{5}{|l|}{ Presentation } \\
\hline $\begin{array}{l}\text { Intracerebral } \\
\text { hemorrhage }\end{array}$ & $144(50.0)$ & & $92(59.4)$ & $0(0)$ \\
\hline Seizure(s) & $124(43.1)$ & $88(61.1)$ & $52(34.2)$ & $36(58.1)$ \\
\hline Eloquence & $164(56.9)$ & $76(52.8)$ & $81(52.9)$ & $24(38.7)$ \\
\hline \multicolumn{5}{|l|}{ Treatment } \\
\hline $\begin{array}{l}\text { Microsurgery } \\
\text { alone }\end{array}$ & $244(84.7)$ & $121(84.0)$ & $146(94.8)$ & $58(93.5)$ \\
\hline $\begin{array}{l}\text { Presurgical } \\
\text { embolization }\end{array}$ & $39(13.5)$ & $21(14.6)$ & $5(3.2)$ & $3(4.9)$ \\
\hline $\begin{array}{l}\text { Prior radiosur- } \\
\text { gery }\end{array}$ & $11(3.8)$ & $4(2.8)$ & $4(2.6)$ & $1(1.6)$ \\
\hline \multicolumn{5}{|l|}{ Deficit } \\
\hline $\begin{array}{l}\text { Any permanent } \\
\text { deficit }\end{array}$ & $35(12.2)$ & $24(16.7)$ & $12(7.8)$ & 7 (11.3) \\
\hline $\begin{array}{l}\text { Significant } \\
\text { permanent } \\
\text { deficit }\end{array}$ & $17(5.9)$ & $11(7.6)$ & $5(3.2)$ & $2(3.2)$ \\
\hline Mortality & 5 & 1 & 3 & 0 \\
\hline
\end{tabular}

* Data are presented as the number of patients (\%) unless indicated otherwise.

of the superficial supplying vessels first, dissection of the AVM from the surrounding brain tissue, exposure of the surfaces of the nidus by removing existing blood clots, and, as the last step, division of the draining vein. AVMs that reached deep into the white matter necessitated the occasional use of microclips for fragile, deep white matter feeders or draining veins. AVMs close to the motor cortex or motor tract have been monitored with evoked potentials and motor evoked potentials since $1997 .^{17,27}$ In cases with uncomplicated hemostasis, patients were extubated early in the intensive care unit and transferred to the ward the next day. Patients with difficult hemostasis were kept in the intensive care unit overnight with a regimen to maintain maximum systolic blood pressure $\leq 100 \mathrm{~mm}$ $\mathrm{Hg}$ and were allowed to wake up the next day. After 24 hours of uneventful observation in the intensive care unit, these patients were transferred to the ward. All patients underwent routine angiography during the 1st week and, in later years, usually immediately after surgery. In 1 case, 2 surgeries were needed for complete obliteration. In 2 cases, newly formed AVMs were found several years later despite negative findings on early angiograms.

\section{Statistical Analysis}

To analyze the descriptive population statistics and potential associations of factors with postoperative outcome, we used SPSS (version 20, IBM). The t-test was used for numerical data, and the Fisher exact test was used for categorical data. Statistical significance was assessed as $\mathrm{p}<$ 0.05 .

\section{Results}

\section{Demographic Data of All Patients}

The demographic data and key AVM features of all patients are described in Table 1, and different subgroups are described in Tables 1 and 2.

In total, 134 patients were female, the mean patient age was 35.3 years (range 1-72 years), and the number of pediatric cases (age $<18$ years) was 38 (13.2\%). Sixty-two patients underwent surgery in Erlangen and 226 in Bonn. In total, $50.0 \%$ of patients presented with intracerebral hemorrhage and $43.1 \%$ of patients presented with seizures.

The occlusion rates, as demonstrated on early postoperative digital subtraction angiography, were $99 \%$ for the total cohort and $98.7 \%$ for patients with small AVMs. In 1 case, 2 surgeries were needed for complete obliteration. In 2 cases, newly formed AVMs were found several years later despite negative early angiograms.

Surgical morbidity, which consisted of all events without neurological sequelae, such as urinary tract infection, pneumonia, superficial wound problems, pulmonary embolism, subgaleal CSF accumulation, and meningitis, were seen in $9.7 \%$ of patients without permanent damage. Early postoperative neurological worsening was seen in $39.2 \%$ of patients, most of which was mild and transient, but $12.2 \%$ of patients had permanent neurological changes, of which $5.9 \%$ had significant changes. The proportion of patients in the entire cohort with a preoperative mRS score $<2$ was $63.9 \%$, and postoperatively this proportion was $70.7 \%$.

\section{Changes Over Time}

The following changes were noted: eloquently located cases increased in number, cases with deep venous drainage were more frequent, and the use of presurgical embolization increased. Since the late 1990s, the selection of cases to be operated on has focused on Spetzler-Martin Grades I to III. There were no operations for Spetzler- 
TABLE 2. Data of all ARUBA-eligible patients compared with Spetzler-Martin Grade I and II, ARUBA-eligible patients*

\begin{tabular}{|c|c|c|}
\hline Variable & $\begin{array}{l}\text { All ARUBA- } \\
\text { Eligible } \\
\text { Patients }\end{array}$ & $\begin{array}{c}\text { ARUBA-Eligible } \\
\text { Spetzler-Martin } \\
\text { Grade I \& II Patients }\end{array}$ \\
\hline Total & 104 & 63 \\
\hline \multicolumn{3}{|l|}{ Sex } \\
\hline Male & $56(53.8)$ & $32(50.8)$ \\
\hline Female & $48(46.2)$ & $31(49.2)$ \\
\hline Mean age, yrs & 38.4 & 40.4 \\
\hline \multicolumn{3}{|l|}{ Spetzler-Martin grade } \\
\hline 1 & $21(20.2)$ & $21(33.3)$ \\
\hline II & $42(40.4)$ & $42(66.7)$ \\
\hline III & $29(27.9)$ & $0(0)$ \\
\hline IV & $12(11.5)$ & $0(0)$ \\
\hline V & $0(0)$ & $0(0)$ \\
\hline \multicolumn{3}{|l|}{ Size } \\
\hline$<3 \mathrm{~cm}$ & $50(48.1)$ & $43(68.3)$ \\
\hline $3-6 \mathrm{~cm}$ & $54(51.9)$ & $20(31.7)$ \\
\hline$>6 \mathrm{~cm}$ & $0(0)$ & $0(0)$ \\
\hline \multicolumn{3}{|l|}{ Venous drainage } \\
\hline $\begin{array}{l}\text { Deep (w/ or w/o superficial } \\
\text { drainage) }\end{array}$ & $35(33.7)$ & $7(11.1)$ \\
\hline Seizure(s) & $65(62.5)$ & $37(58.7)$ \\
\hline Eloquence & $54(51.9)$ & $23(36.5)$ \\
\hline \multicolumn{3}{|l|}{ Treatment } \\
\hline Microsurgery alone & $104(100)$ & $63(100)$ \\
\hline Presurgical embolization & $0(0)$ & $0(0)$ \\
\hline Prior radiosurgery & $0(0)$ & $0(0)$ \\
\hline \multicolumn{3}{|l|}{ Deficit } \\
\hline Any permanent deficit & $18(17.3)$ & $9(14.3)$ \\
\hline Significant permanent deficit & $8(7.7)$ & $2(3.2)$ \\
\hline Mortality & 0 & 0 \\
\hline
\end{tabular}

* Data are presented as number (\%) unless indicated otherwise.

Martin Grade V lesions after 1999, and there were 3 Spetzler-Martin Grade V lesions between 1985 and 1999.

\section{Presurgical Treatment}

One patient underwent multiple treatments at an outside institution prior to surgical treatment at our department, including partial resection, embolization, and radiosurgery. Altogether, 39 patients underwent presurgical embolization, and 11 patients had prior radiosurgery. In detail, 6 patients $(2.1 \%)$ underwent presurgical radiosurgery and embolization, 33 patients $(11.5 \%)$ underwent presurgical embolization alone, and 5 patients $(1.7 \%)$ underwent radiosurgery alone; the patients who underwent radiosurgery alone were referred because of the lack of success. Presurgical embolization was used until 1996 in 11.7\% (19 of 163) of cases, between 1997 and 2003 in $14.7 \%$ of cases, and between 2004 and 2012 in $16.4 \%$ of cases. Overall, $51.3 \%$ of embolizations were performed in $20(22.9 \%)$ of 90 Grade III cases, and $25.6 \%$ of embolizations were per- formed in 10 (32.3\%) of 31 Grade IV and V cases. Embolization was performed in 2 of 53 Spetzler-Martin Grade I AVMs (3.8\%) with the hope of achieving total occlusion and in 7 of 114 Spetzler-Martin Grade II AVMs (6.1\%). For Spetzler-Martin Grade II AVMs, embolization was used for AVMs that were located in or close to the eloquent cortex and showed the angiographic criteria of high flow. Surgery was usually performed within 1 or 2 days after embolization. All cases were discussed in the neuroradiological radiography conference, and a joint decision was made by the neurosurgeon and neuroradiologist.

\section{Spetzler-Martin Grades, Size, and Eloquence}

There were 53 Spetzler-Martin Grade I lesions (18.4\%), 114 Spetzler-Martin Grade II lesions (39.6\%), 90 SpetzlerMartin Grade III lesions (31.3\%), 28 Spetzler-Martin Grade IV lesions (9.7\%), and 3 Spetzler-Martin Grade V lesions (1\%). Ponce Class A (Spetzler-Martin Grades I and II combined) comprised 167 cases (58\%), and combined Spetzler-Martin Grade I to III AVMs accounted for 257 cases $(89.2 \%)$.

The AVM diameter was $<3 \mathrm{~cm}$ in 154 cases (53.5\%), 3 to $6 \mathrm{~cm}$ in 129 cases $(44.8 \%)$, and $>6 \mathrm{~cm}$ in 5 cases $(1.7 \%)$. In the total series, an eloquent location was present in 164 cases $(56.9 \%)$. Eloquent locations included a dominant sylvian/temporoparietal location, visual pathways, precentral/central location, basal ganglia, brainstem, cerebellar nuclei, corpus callosum, and postcentral gyrus. Details on the outcomes of the preoperative seizures in this patient series have been published separately. ${ }^{30}$

Five cases were excluded because surgery was interrupted before AVM removal: 1 intrapontine lesion, which was thought to be a bleeding cavernoma, was in fact an AVM and thereby surgery was considered too dangerous. Another lesion, which was thought to lie within the parapontine cistern, had spread circumferentially around the brainstem and was left intact. In 3 other cases, massive bleeding occurred during craniotomy (blood loss was approximately $4 \mathrm{~L}$ each), and surgery was interrupted and embolization planned. These patients did not wish to go ahead with embolization and surgery.

\section{Small AVM Subgroup}

So called small AVMs measuring less than $3 \mathrm{~cm}$ in diameter are ideal candidates for radiosurgery and accounted for 154 cases (53.5\%). This subgroup included a higher proportion of Spetzler-Martin Grade I and II lesions (n $=126 ; 81.8 \%$ ) and 28 Spetzler-Martin Grade III lesions $(18.2 \%)$. More patients presented with a hemorrhage than in the nonsmall group $(59.7 \%$ vs $38.8 \%)$. The incidence of an eloquent location was not significantly different (52.9\% small vs $61.9 \%$ nonsmall lesions). Deep venous drainage was less frequent in the small group (28.4\%) than in the nonsmall group (42.5\%). Presurgical embolization was used in $3.2 \%$ of small AVMs (5 cases) versus $25.4 \%$ of nonsmall AVMs. Microsurgery was used as the sole intervention in $94.8 \%$ of small AVMs versus $73.1 \%$ of nonsmall AVMs. The rebleeding rate was $0.7 \%$, and the occlusion rate was $98.7 \%$. The rate of permanent significant postoperative neurological worsening was $3.2 \%$ in the 
TABLE 3. Permanent new deficits with respect to Spetzler-Martin grade in all patients available for follow-up

\begin{tabular}{lccc}
\hline $\begin{array}{c}\text { Spetzler-Martin } \\
\text { Grade }\end{array}$ & $\begin{array}{c}\text { No. of } \\
\text { Patients }\end{array}$ & $\begin{array}{c}\text { No. w/ } \\
\text { Permanent New } \\
\text { Deficit (\%) }\end{array}$ & $\begin{array}{c}\text { No. w/ Permanent } \\
\text { Significant New } \\
\text { Deficit (\%) }\end{array}$ \\
\hline I & 53 & $5(9.4)$ & $1(1.9)$ \\
\hline II & 114 & $7(6.1)$ & $2(1.8)$ \\
\hline III & 90 & $6(6.7)$ & $3(3.3)$ \\
\hline IV & 28 & $15(53.6)$ & $10(35.7)$ \\
\hline I \& II (Ponce Class A) & 167 & $12(7.2)^{*}$ & $3(1.8)^{*}$ \\
\hline III \& IV (Ponce & 118 & $21(17.8)^{*}$ & $13(11)^{*}$ \\
Classes B \& C) & & & $17(5.9)$ \\
\hline Total & 288 & $35(12.2)$ & \\
\hline
\end{tabular}

${ }^{*} p<0.05$. The difference between both Ponce groups was significant.

small group versus $8.2 \%$ in the nonsmall group. Mortality was $1.9 \%$ in the small group versus $1.5 \%$ in the non-small group.

\section{Hemorrhagic Versus Unruptured Presentation}

Half of all patients $(n=144)$ presented with a hemorrhage. This group contained significantly more small AVMs (63.9\% vs 43.1\%), markedly fewer Spetzler-Martin Grade IV and V AVMs (7.6\% vs $13.9 \%)$, and a similar rate of deep venous drainage (35.4\% vs $34.7 \%$ ) compared with the unruptured cases. Microsurgery as the sole treatment was used in a similar percentage of cases $(85.4 \%$ vs $84.0 \%)$.

Of all 144 unruptured cases, 62 were small unruptured AVMs and 78 were unruptured Ponce Class A AVMs. The permanent new deficit rate was higher in the unruptured group (16.7\% vs $7.6 \%)$. Similarly, permanent significant deficits were more frequent $(7.6 \%)$ compared with the hemorrhagic group (4.2\%).

\section{The Ponce Class A Unruptured Subgroup}

The number of combined unruptured Ponce Class A (combined Spetzler-Martin Grade I and II) AVMs was 78 of a total 167 Spetzler-Martin Grade I or II AVMs. This included 26 Spetzler-Martin Grade I and 52 Spetzler-Martin Grade II AVMs. Thirty-one percent of these AVMs (n $=24$ ) were between 3 and $6 \mathrm{~cm}$ in diameter, two-thirds were in noneloquent locations, presurgical embolization was used in 6 cases, and $94.9 \%$ were treated by microsurgery alone. A new postoperative deficit was observed in $12.8 \%$ of cases, but permanent new significant deficits were noted in less than $2.6 \%$ of cases and there were 0 instances of mortality. The deficit rates of the Ponce Class A group are shown in Table 3.

Unruptured cases were associated with more permanent deficits and more significant permanent deficits than hemorrhagic cases with a similar size or Spetzler-Martin grade.

\section{ARUBA-Eligible Subgroup}

A total of 104 cases that would have fulfilled the in- clusion criteria for the ARUBA study-i.e., excluding pediatric patients and patients with prior therapy and a preexisting deficit with $\mathrm{mRS}$ score $>1$-were identified, including 21 Spetzler-Martin Grade I, 42 Spetzler-Martin Grade II, 29 Spetzler-Martin Grade III, and 12 SpetzlerMartin Grade IV AVMs. The majority of cases had superficial venous drainage $(85.6 \%)$, and $51.9 \%$ had diameters between 3 and $6 \mathrm{~cm}$. The preoperative mRS score was < 2 in all 104 cases, and the postoperative score was $<2$ in $89.6 \%$ of cases with an available mRS grade (96 of 104 cases). A new significant and permanent deficit was seen in $7.7 \%$ of cases. Treatment-related mortality in the ARUBA subgroup was 0. For the entire ARUBA subgroup, the available outcomes expressed in terms of the percentage of cases with mRS score > 1 was $10.4 \%$ (10 of 96 cases).

The ARUBA Ponce Class A subgroup included 63 patients. For Spetzler-Martin Grade I AVMs, the percentage of patients with mRS score $>1$ was $9.5 \%$ if all deaths were counted, but only $4.8 \%$ if only AVM-related deaths were counted. For Spetzler-Martin Grade II outcomes, the percentage of patients with $\mathrm{mRS}$ score $>1$ was $4.8 \%$. For Ponce Class A patients, the percentage of patients with $\mathrm{mRS}$ score $>1$ was $6.3 \%$, but if AVM-unrelated deaths were left out the percentage was $4.8 \%$.

The deficit rates of the study cohort compared with the deficit rates in the different subgroups are shown in Table 4.

\section{Risk Factors}

Various age limits were examined to try to define an age group with a different risk profile, but there were no significant differences in terms of the frequency of significant permanent deficits between older and younger patients $(p>0.05)$. Similarly, for patients younger than 18 years, nonhemorrhagic presentation had a tendency toward worse outcome, but this difference did not reach statistical significance $(\mathrm{p}=0.32)$. Small AVM diameter was associated with better outcome $(\mathrm{p}=0.047)$, as were Spetzler-Martin Grades I and II $(\mathrm{p}<0.01)$ and a noneloquent location $(\mathrm{p}=0.015)$. Deep venous drainage did not lead to worse outcome $(\mathrm{p}=0.12)$.

\section{Complications}

The deficit rates for the different Spetzler-Martin grades are shown in Table 3 . While the permanent significant deficit rates are below 2\% for Spetzler-Martin Grade I and II lesions, they increase to $3.3 \%$ for Spetzler-Martin Grade III lesions. Comparing Ponce Class A with Ponce Classes B and C (i.e., Spetzler-Martin Grade III and IV combined), Ponce Class A has a significantly lower permanent deficit rate and very much lower rate of significant deficits $(\mathrm{p}<$ $0.05)$.

\section{Discussion}

\section{Indications for Surgery and Embolization Over Time}

The analysis of the total caseload, including outpatients, clearly shows the fact that the surgeon had become more restrictive regarding Spetzler-Martin Grade IV and V AVMs. Rather early, the surgeon started focusing on surgical intervention for Spetzler-Martin Grades I to III. The discussion on whether Grade III AVMs should not be 
TABLE 4. Permanent new deficits and significant permanent new deficits in the study cohort and different subgroups

\begin{tabular}{lcccccc}
\hline \multicolumn{1}{c}{ Variable } & $\begin{array}{c}\text { All } \\
\text { AVMs }\end{array}$ & $\begin{array}{c}\text { All Unruptured } \\
\text { AVMs }\end{array}$ & $\begin{array}{c}\text { All Hemorrhagic } \\
\text { AVMs }\end{array}$ & $\begin{array}{c}\text { Small Unruptured } \\
\text { AVMs }\end{array}$ & $\begin{array}{c}\text { All ARUBA- } \\
\text { Eligible AVMs }\end{array}$ & $\begin{array}{c}\text { ARUBA-Eligible Spetzler-Martin } \\
\text { Grade I \& II, Ponce Class A AVMs }\end{array}$ \\
\hline No. of patients & 288 & 144 & 144 & 62 & 104 & 63 \\
\hline$\%$ w/ permanent new deficit & 12.2 & 16.7 & 7.6 & 11.3 & 17.3 & 14.3 \\
\hline $\begin{array}{l}\% \text { w/ significant permanent } \\
\text { new deficit }\end{array}$ & 5.6 & 7.6 & 4.2 & 3.2 & 7.7 & 3.2 \\
\hline \begin{tabular}{l}
$\%$ mortality \\
\hline
\end{tabular} & 1.7 & 0.7 & 2.8 & 0 & 0 & 0 \\
\hline
\end{tabular}

considered differently from Grades I and II lesions came on only recently. ${ }^{4,14}$ The relatively high number of AVM cases seen, but not operated on, demonstrates that this is a highly selected series of cases. Many high-risk cases were not selected for microsurgery on purpose. This, however, does not mean that the operated cases were mainly simple lesions, as can be deducted from the high rate of eloquently located AVMs and the deficit and mortality rates in the lower Spetzler-Martin grades. Of the cases rejected for surgery, a large proportion was outright inoperable, and another large group was not necessarily too big but located in areas that are usually considered very risky or inoperable. There were a number of operable cases that could have been operated on, but after a careful discussion of the pros and cons of the 3 treatment methods, the patients decided against surgery.

In general, the results of this series do not allow generalized conclusions about the treatment results of cerebral AVM. Unfortunately, when we started to collect data in the mid-1980s, no decision was made to collect data on the rejected cases and nonoperated cases in parallel to those that were operated on. Thus, a comparison between surgical cases and conservatively managed cases is impossible.

\section{Use of Embolization and Radiosurgery}

In a previous paper, ${ }^{22}$ a comparison of 3 treatment modalities-microsurgery, embolization, and radiosurgery-was performed, and the conclusion then was that "microsurgery for small AVMs is superior to radiosurgery or interventional neuroradiology because of its high rate of efficacy and low rate of permanent morbidity and because immediate cure of the AVMs can be achieved in the vast majority of patients." The main reason for the restrictive use of preembolization was the important fact that by combining 2 treatment modalities, one also adds the complication rate of 1 modality to the complication rate of the second modality. The potential reduction in side effects after the use of preembolization has not been convincingly demonstrated, nor has the introduction of Onyx improved the rate of side effects. ${ }^{3,26}$ On the contrary, 2 studies found increased complication rates after preembolization. ${ }^{15,28}$ In the 1990s and early 2000s, embolization series usually showed a comparable rate of new deficits $(0 \%-22 \%)$ and even certain mortality $(0 \%-4.3 \%) .{ }^{19,29}$ A recent review of approximately 1300 mostly low-grade AVMs found a mortality rate of $1.6 \%$, morbidity rate of $6.2 \%$, and an occlusion rate of $29 \%$. In a recent statement by Lawton et al., ${ }^{9}$ the disadvantages of the endovascular and radiosurgical treatments compared to microsurgery were highlighted.
Radiosurgery also has a permanent morbidity rate and mortality rate between $0 \%$ and $3 \%$ due to persistent bleeding. ${ }^{18}$ We certainly had the impression that embolization in high-flow AVMs made resection easier, but it is difficult to conclude that preembolization led to a reduction in the complication rates.

\section{The ARUBA Study}

In the ARUBA study-in which only a minority of cases underwent microsurgery alone and a small group underwent a combination of embolization plus microsurgery-conservatively managed cases had a markedly lower stroke and mortality rate $(10.1 \%$ vs $30.7 \%)$. The lower rate for conservatively managed AVMs was confirmed in the conclusions of a Scottish population-based study. ${ }^{1}$ However, looking closely at the defined primary outcome, the results for treated and untreated patients were similar after 4 years of follow-up.

In fact, the treatment group in the ARUBA study is more representative of the various nonmicrosurgical treatment modalities and their complications, or as phrased by Russin and Cohen-Gadol,20 "Many of the outcome data in the treatment arm of the ARUBA trial are contaminated by prior therapeutic trends that have since been largely abandoned because of high complication rates and low obliteration rates." In general, it would be wrong to draw significant conclusions regarding the value of microsurgical treatment from the ARUBA study since it only considers unruptured AVMs. The frequently heard assumption that microsurgery for AVMs, in general, has suffered a severe setback by the ARUBA study is incorrect.

\section{Comparing Outcomes for Spetzler-Martin Grades}

The inhomogeneity of Spetzler-Martin Grade III AVMs has been described by Lawton, ${ }^{8}$ who proposed that Spetzler-Martin Grade III AVMs need to be further specified as low-risk and high-risk lesions, thereby leading to the recommendation of more individualized indications for Spetzler-Martin Grade III lesions. ${ }^{8,10,24}$ Spetzler and Ponce $^{24}$ also worked out that the risk profiles for SpetzlerMartin Grade I and II AVMs are similar but very different from Spetzler-Martin Grade III AVMs, which is a finding confirmed by this study. Several known risk factors, which may explain the outcome differences, were identified: 29 of 90 Spetzler-Martin Grade III AVMs were small with deep venous drainage and an eloquent location. The other 61 Spetzler-Martin Grade III lesions were $>3 \mathrm{~cm}$, which is also associated with higher risk. Lawton ${ }^{8}$ has demonstrated that within Spetzler-Martin Grade III lesions, morbidity in- 
creases when the size is $>3 \mathrm{~cm}$ and increases significantly when the location is eloquent, which is a finding that is also reported in our own study on risk factors. ${ }^{23}$

Looking at the complication rates for the various Spetzler-Martin grades, this series shows markedly higher rates for Ponce Class B and C lesions compared with Ponce Class A lesions.

Permanent deficits occur in around $4.2 \%$ of combined Spetzler-Martin Grade I and II lesions, and this increases to around 6.7\% for Spetzler-Martin Grade III lesions (Table 3). The permanent significant deficit rates for SpetzlerMartin Grade I and II versus Spetzler-Martin Grade III lesions show a larger difference (1\% vs 3.3\%). The rate of permanent deficits in Steiger et al.'s series of 69 SpetzlerMartin Grade I and II AVMs was also markedly lower than in their 22 Spetzler-Martin Grade III lesions. ${ }^{25}$

Looking at permanent significant deficit rates for Spetzler-Martin Grade I and II versus Spetzler-Martin Grade III lesions in this cohort (1\% vs 3.3\%), it is indeed worth discussing if unruptured Spetzler-Martin Grade III lesions should be routinely recommended for microsurgery. A similar conclusion had been reached earlier by Morgan ${ }^{14}$ and was recently supported by El Hammady and Heros. ${ }^{4}$

\section{Outcomes of the ARUBA-Eligible Subgroup}

There have been a number of studies in which AVMs fulfilling the ARUBA criteria were operated on, and it was clearly demonstrated that, at least for Spetzler-Martin Grade I and II AVMs, patients who undergo microsurgical removal of the AVM have better outcomes than those treated with observation. ${ }^{2,13,21}$ This study confirms these results. The number of instances of postoperative mRS score $>1$ among 59 total Ponce Grade A cases with available mRS score was $3(5.1 \%)$. The permanent new significant deficit rate was 3.2\% in the ARUBA-eligible Spetzler-Martin Grade I and II group, with both ARUBA-eligible groups having 0 instances of mortality. These figures are lower than those of the interventional and observational arms of the ARUBA study, where conservative management resulted in a $10.1 \%$ risk of stroke or death and interventional management resulted in a $30.7 \%$ risk. In light of this ongoing discussion, several authors continue to recommend Spetzler-Martin Grade I and II AVMs for microsurgery as the best treatment option. $., 11,13,16,20,25,26$

\section{Unruptured Versus Ruptured AVM}

Unruptured AVMs had higher complication rates in the total, small AVM, and Spetzler-Martin Grade I and II subgroups, which is similar to the findings of Theofanis et al. ${ }^{28}$ and Lawton et al. ${ }^{9}$ The initial neurological deterioration was frequently higher, but usually regressed significantly. It seems that being "unruptured" is a more important determinant for postoperative deficit than AVM size alone, which is a finding that was also described by Theofanis et al. ${ }^{28}$ and Lawton et al. ${ }^{9}$ A potential explanation is the need to perform a more expansive dissection through the unaffected brain.

The outcomes of the unruptured subgroups were better than for the corresponding ARUBA subgroups. The rate of permanent significant deficits was lowest for unruptured Spetzler-Martin Grade I and II lesions (1.0\%) compared with ARUBA Spetzler-Martin Grade I and II lesions (3.2\%). The outcomes for Spetzler-Martin Grade III lesions show a 3-times-higher rate of permanent significant deficit, both for ARUBA Spetzler-Martin Grade III and unruptured Spetzler-Martin Grade III lesions (10.3\% and $6.5 \%$, respectively). The unruptured small AVM subgroup had better outcomes than the interventional therapy group and the medical management group of the ARUBA study. Thus, the criterion of "small" was as indicative as "Spetzler-Martin Grade I and II" in terms of a potential good outcome.

\section{Strengths and Weaknesses of the Study}

The series includes every patient who underwent microsurgical AVM removal in the observation period by the same surgeon. All patients underwent early angiography, and data were prospectively collected at the 3- to 6-month follow-up examinations. Follow-up data (i.e., at least 6 months [range 6-326 months]) were obtained from a high proportion of the cases $(72.4 \%)$. There are several limitations of the study. Due to the selection process for indicating microsurgical removal, no generalized conclusions regarding the value of microsurgery in an unselected population of AVMs can be drawn. Compared with randomized studies, there are also inherent shortcomings to single-institution series. Prospective data collection is a positive feature, however.

Another limitation is that no specific information about the presence of intranidal aneurysms was collected since the 1980s, and the significance of these aneurysms was not yet well established. Sorely missed in the light of recent discussions are follow-up data on the patients who were seen but not operated on, although we were able to describe the number of conservatively managed cases for many years.

\section{Conclusions}

Microsurgical resection of a cerebral AVM has a high cure rate. Focusing microsurgical AVM resection on unruptured lesions $<3 \mathrm{~cm}$ or Spetzler-Martin Grade I and II lesions, including ruptured ones, is a good strategy for minimizing long-term morbidity. Well-selected microsurgical cases lead to better outcomes than with multimodal interventions, as in the ARUBA treatment arm, or conservative treatment alone. Long-term prospective data collection is valuable.

\section{Acknowledgments}

Drs. R. Steinmeier and C. Pavlidis helped build the database. C. von der Brelie added some late follow-up data.

\section{References}

1. Al-Shahi Salman R, White PM, Counsell CE, du Plessis J, van Beijnum J, Josephson CB, et al: Outcome after conservative management or intervention for unruptured brain arteriovenous malformations. JAMA 311:1661-1669, 2014

2. Bervini D, Morgan MK, Ritson EA, Heller G: Surgery for unruptured arteriovenous malformations of the brain is better than conservative management for selected cases: a prospective cohort study. J Neurosurg 121:878-890, 2014 
3. Crowley RW, Ducruet AF, Kalani MY, Kim LJ, Albuquerque FC, McDougall CG: Neurological morbidity and mortality associated with the endovascular treatment of cerebral arteriovenous malformations before and during the Onyx era. $\mathbf{J}$ Neurosurg 122:1492-1497, 2015

4. Elhammady MS, Heros RC: Management of incidental cerebral AVMs in the post-ARUBA era. J Neurosurg 121:10111014, 2014

5. Flemming KD, Brown RD: The natural history of intracranial vascular malformations, in Winn HR (ed): Youmans Neurological Surgery, ed 6. Philadelphia: Elsevier Saunders, 2011, Vol 4, pp 4016-4033

6. Laakso A, Dashti R, Seppänen J, Juvela S, Väärt K, Niemelä $\mathrm{M}$, et al: Long-term excess mortality in 623 patients with brain arteriovenous malformations. Neurosurgery 63:244255,2008

7. Lawton MT: The role of AVM microsurgery in the aftermath of a randomized trial of unruptured brain arteriovenous malformations. AJNR Am J Neuroradiol 36:617-619, 2015

8. Lawton MT: Spetzler-Martin Grade III arteriovenous malformations: surgical results and a modification of the grading scale. Neurosurgery 52:740-749, 2003

9. Lawton MT, Du R, Tran MN, Achrol AS, McCulloch CE, Johnston SC, et al: Effect of presenting hemorrhage on outcome after microsurgical resection of brain arteriovenous malformations. Neurosurgery 56:485-493, 2005

10. Lawton MT, Kim H, McCulloch CE, Mikhak B, Young WL: A supplementary grading scale for selecting patients with brain arteriovenous malformations for surgery. Neurosurgery 66:702-713, 2010

11. Meling TR, Proust F, Gruber A, Niemela M, Regli L, Roche PH, et al: On apples, oranges, and ARUBA. Acta Neurochir (Wien) 156:1775-1779, 2014

12. Mohr JP, Parides MK, Stapf C, Moquete E, Moy CS, Overbey JR, et al: Medical management with or without interventional therapy for unruptured brain arteriovenous malformations (ARUBA): a multicentre, non-blinded, randomised trial. Lancet 383:614-621, 2014

13. Moon K, Levitt MR, Almefty RO, Nakaji P, Albuquerque FC, Zabramski JM, et al: Safety and efficacy of surgical resection of unruptured low-grade arteriovenous malformations from the modern decade. Neurosurgery 77:948-953, 2015

14. Morgan MK: Therapeutic decision making, in Winn HR (ed): Youmans Neurological Surgery, ed 6. Philadelphia: Elsevier Saunders, 2011, Vol 4, pp 4034-4048

15. Morgan MK, Davidson AS, Koustais S, Simons M, Ritson EA: The failure of preoperative ethylene-vinyl alcohol copolymer embolization to improve outcomes in arteriovenous malformation management: case series. J Neurosurg 118:969-977, 2013

16. Nerva JD, Mantovani A, Barber J, Kim LJ, Rockhill JK, Hallam DK, et al: Treatment outcomes of unruptured arteriovenous malformations with a subgroup analysis of ARUBA (A Randomized Trial of Unruptured Brain Arteriovenous Malformations)-eligible patients. Neurosurgery 76:563-570, 2015

17. Neuloh G, Schramm J: Motor evoked potential monitoring for the surgery of brain tumours and vascular malformations. Adv Tech Stand Neurosurg 29:171-228, 2004

18. Potts MB, Lau D, Abla AA, Kim H, Young WL, Lawton MT: Current surgical results with low-grade brain arteriovenous malformations. J Neurosurg 122:912-920, 2015

19. Potts MB, Zumofen DW, Raz E, Nelson PK, Riina HA: Curing arteriovenous malformations using embolization. Neurosurg Focus 37(3):E19, 2014

20. Russin J, Cohen-Gadol AA: Editorial. What did we learn from the ARUBA trial? Neurosurg Focus 37(3):E9, 2014

21. Rutledge WC, Abla AA, Nelson J, Halbach VV, Kim H,
Lawton MT: Treatment and outcomes of ARUBA-eligible patients with unruptured brain arteriovenous malformations at a single institution. Neurosurg Focus 37(3):E8, 2014

22. Schaller C, Schramm J: Microsurgical results for small arteriovenous malformations accessible for radiosurgical or embolization treatment. Neurosurgery 40:664-674, 1997

23. Schaller C, Schramm J, Haun D: Significance of factors contributing to surgical complications and to late outcome after elective surgery of cerebral arteriovenous malformations. J Neurol Neurosurg Psychiatry 65:547-554, 1998

24. Spetzler RF, Ponce FA: A 3-tier classification of cerebral arteriovenous malformations. Clinical article. J Neurosurg 114:842-849, 2011

25. Steiger HJ, Fischer I, Rohn B, Turowski B, Etminan N, Hänggi D: Microsurgical resection of Spetzler-Martin grades 1 and 2 unruptured brain arteriovenous malformations results in lower long-term morbidity and loss of quality-adjusted life-years (QALY) than conservative management-results of a single group series. Acta Neurochir (Wien) 157:12791287,2015

26. Steiger HJ, Schaller K: Treatment of unruptured brain AVM in the aftermath of ARUBA and the Scottish Audit of Intracranial Vascular Malformations. Acta Neurochir (Wien) 157:1291-1293, 2015

27. Taniguchi M, Cedzich C, Schramm J: Modification of cortical stimulation for motor evoked potentials under general anesthesia: technical description. Neurosurgery 32:219-226, 1993

28. Theofanis T, Chalouhi N, Dalyai R, Starke RM, Jabbour P, Rosenwasser RH, et al: Microsurgery for cerebral arteriovenous malformations: postoperative outcomes and predictors of complications in 264 cases. Neurosurg Focus 37(3):E10, 2014

29. van Beijnum J, van der Worp HB, Buis DR, Al-Shahi Salman R, Kappelle LJ, Rinkel GJ, et al: Treatment of brain arteriovenous malformations: a systematic review and meta-analysis. JAMA 306:2011-2019, 2011

30. von der Brelie C, Simon M, Esche J, Schramm J, Boström A: Seizure outcomes in patients with surgically treated cerebral arteriovenous malformations. Neurosurgery 77:762-768, 2015

\section{Disclosures}

The authors report no conflict on interest concerning the materials or methods used in the study or the findings specified in this paper.

\section{Author Contributions}

Conception and design: Boström, Schramm. Acquisition of data: Boström, Schaller, Esche. Analysis and interpretation of data: Boström, Schramm, Schaller. Drafting the article: Boström, Schramm. Critically revising the article: Schramm. Approved the final version of the manuscript on behalf of all authors: Boström. Statistical analysis: Boström, Esche. Administrative/technical/ material support: Schramm. Study supervision: Boström, Schramm.

\section{Supplemental Information \\ Previous Presentations}

Portions of this work were presented in an oral form at the Annual Meeting of the Vascular Section of the German Society of Neurosurgery in Essen, Germany, on September 12, 2015.

\section{Correspondence}

Azize Boström, Department of Neurosurgery, University of Bonn, Sigmund-Freud-Str. 25, Bonn 53105, Germany. email: Azize. Bostroem@ukb.uni-bonn.de. 